\title{
ATUAL ESTADO DE PROTEÇÃO DOS MORCEGOS AMEAÇADOS DE EXTINÇÃO NO ESTADO DO RIO DE JANEIRO
}

\author{
Luciana Moraes Costa ${ }^{1^{*}}$, Gisele Winck ${ }^{2}$, Júlia Lins Luz ${ }^{3}$, Helena Godoy Bergallo ${ }^{1}$ \& Carlos \\ Eduardo Lustosa Esbérard ${ }^{4}$
}

\begin{abstract}
${ }^{1}$ Universidade do Estado do Rio de Janeiro, Instituto de Biologia, Departamento de Ecologia, Laboratório de Ecologia de Mamíferos, Rua São Francisco Xavier, 524, CEP 20550-013, Rio de Janeiro, RJ, Brasil.

² Université Grenoble Alpes, Laboratoire d’Ecologie Alpine, UMR CNRS 5553, Grenoble Cedex 9, 38041, France.

${ }^{3}$ Universidade Federal do Rio de Janeiro, Departamento de Ecologia, Laboratório de Vertebrados, Av. Brigadeiro Trompowski, s/n, Cidade Universitária, Ilha do Fundão, CEP 21941-599, Rio de Janeiro, RJ, Brasil.

${ }^{4}$ Universidade Federal Rural do Rio de Janeiro, Instituto de Biologia, Laboratório de Diversidade de Morcegos, BR-457, Km 47, CEP 23890-000, Seropédica, RJ, Brasil.
\end{abstract}

E-mails: costalucianam@gmail.com (*autor correspondente); gwinck@gmail.com; julialinsluz@yahoo.com.br; nena. bergallo@gmail.com; ceesberard@gmail.com

\begin{abstract}
Resumo: A fragmentação e a supressão do habitat são fatores que influenciam negativamente a ocorrência dos morcegos, e uma das estratégias para a manutenção de suas populações é a preservação dos ambientes via estabelecimento de Unidades de Conservação (UCs). Estudos que identificam quais espécies não estão protegidas por UCs podem direcionar os esforços para o planejamento de conservação. Para tanto, avaliamos a quantidade de espécies ameaçadas de extinção de morcegos que ocorrem no Estado do Rio de Janeiro e estão protegidas pelo Sistema Nacional de Unidades de Conservação (SNUC), e se há diferenças no número de espécies ameaçadas entre as regiões fitoecológicas. Neste estudo compilamos dados de ocorrência de morcegos entre 1989 e 2018 em 30 UCs e 17 localidades que não estão inseridas em UCs. Registramos três espécies ameaçadas em nível nacional, enquanto em nível regional foram consideradas 11 espécies. Natalus macrourus foi a única espécie ameaçada de extinção nos dois níveis (regional e nacional) que não está protegida pelo SNUC no Estado do Rio de Janeiro. Esta espécie foi capturada nos municípios de Miracema e Cantagalo, que possuem importantes áreas para conservação e preservação de morcegos, mas que não estão sob proteção legal. A Gruta Pedra Santa no município de Cantagalo tem registros de três espécies ameaçadas no nível nacional, sendo assim consideramos ser uma localidade importante para a preservação da biodiversidade, visto que está em uma região de alta degradação ambiental, e com poucos remanescentes de habitat. Algumas espécies de morcegos ameaçadas de extinção não estão ou são pouco protegidas pela rede de UCs do Estado do Rio de Janeiro, em especial as que ocorrem na região de Floresta Estacional Semidecidual.
\end{abstract}

Palavras-chave: áreas protegidas; Brasil; Chiroptera; conservação; Mata Atlântica. 
CURRENT PROTECTION STATUS OF THREATENED BAT SPECIES IN THE STATE OF RIO DE JANEIRO, BRAZIL Habitat fragmentation and obliteration are main factors negatively influencing the occurrence of bats, being the environmental preservation through the establishment of protected areas a fundamental strategy for maintaining bat populations. To identify which species are included in the Brazilian Conservation Units (CU's) network generates some of the main data for conservation planning. Here we evaluate the number of threatened bat species occurring in Rio de Janeiro state and are protected by the National System of Conservation Units (SNUC), and whether there are differences in the number of threatened species among the phytoecological regions. We compiled bat occurrence data between 1989 and 2018 on 30 Protected areas and 17 sites that are not included in the SNUC. We recorded three threatened species at national level and 11 species at regional level. One species (Natalus macrourus) is the only with threatened status at both levels (regional and national) that is not protected by the SNUC in Rio de Janeiro state. This species was captured in Miracema and Cantagalo municipalities, which present important sites for bats conservation and/or preservation with no legal protection whatsoever. We also consider the Gruta Pedra Santa site in Cantagalo municipality an important site for biodiversity preservation: it presents records of three threatened species at national level in a region of high environmental degradation. Some threatened bat species are poorly or not protected by the CUs network established in Rio de Janeiro state, especially those occurring in the semideciduous seasonal forest region.

Keywords: Atlantic forest; Brazil; Chiroptera; conservation; protected areas.

\section{INTRODUÇÃO}

Mudanças drásticas no uso da terra, modificações abruptas no clima e outros distúrbios provocados por ações antrópicas estão acelerando os processos de extinção, os deslocamentos das distribuições geográficas e as mudanças fenológicas das espécies em um ritmo vertiginoso (Tylianakis et al. 2008) e isso não é diferente para os morcegos (Voigt \& Kingston 2016). Estes animais apresentam grande diversidade alimentar (Kalko et al. 1996, Simmons 2005), são importantes como dispersores de sementes, polinizadores e controladores de insetos e pequenos vertebrados, fornecendo assim diversos serviços ecossistêmicos (Reis et al. 2007a, Kunz et al. 2011). As estratégias para a conservação de morcegos devem considerar que esses organismos utilizam diversos ambientes para refúgio e forrageamento (Reis et al. 2007b).

As maiores ameaças aos seus habitats e refúgios são: o desaparecimento de áreas naturais devido ao desmatamento, atividades agropecuárias, mineração e a falta de capacitação taxonômica dos profissionais responsáveis pela elaboração e execução dos programas de controle de morcegos hematófagos (Hutso et al. 2001). O desmatamento consiste em uma das principais ameaças à sobrevivência de muitas espécies de morcegos e pode influenciar negativamente a ocorrência deles (Voigt \& Kingston 2016). A preservação dos ambientes é uma estratégia para a manutenção das populações de morcegos e da biodiversidade em geral e o estabelecimento de áreas protegidas como as Unidades de Conservação (UCs) é uma das formas de preservação. UCs protegem uma parte considerável da biodiversidade brasileira (Oliveira et al. 2017). Porém, isso é verdade em especial para as UCs que possuem uma gestão efetiva, possuindo plano de manejo e que tenham recursos para fiscalizar e fazer a gestão (IBAMA \& WWF-Brasil 2007).

Áreas protegidas podem ser definidas como locais dedicados à proteção e manutenção da diversidade biológica e dos recursos naturais e culturais associados, manejados através de instrumentos legais ou outros instrumentos efetivos (IUCN 1994). São diversos os critérios existentes para a criação de UCs, variando desde aqueles baseados em informações sobre espécies de fauna e flora, até aqueles que dão ênfase apenas a heterogeneidade ambiental (Fearnside \& Ferraz 1995, Rylands \& Pinto 1998, Jennings 2000). As UCs são divididas em dois grupos: Unidades de Proteção Integral e Unidades de Uso Sustentável. A categoria de Proteção Integral visa a preservação da natureza admitindo-se, apenas, o uso indireto dos seus recursos naturais; e a categoria de Uso Sustentável 
tem como objetivo compatibilizar a conservação da natureza com o uso sustentável de parcela dos seus recursos (Bernardo 2007). A efetividade dos sistemas de UCs depende de quão adequadamente podem cumprir sua missão e manter a biodiversidade, além de funcionar em meio a instituições governamentais (Rylands \& Brandon 2005). A contextualização das UCs compreende a análise de pressões, ameaças, vulnerabilidades e o cenário da importância biológica e socioeconômica das UCs (IBAMA \& WWF-Brasil 2007). A importância biológica é avaliada pela: riqueza de espécies raras ameaçadas ou em perigo de extinção, biodiversidade, diversidade ecossistêmica, entre outros (IBAMA \& WWF-Brasil 2007). Porém o conhecimento da biodiversidade dentro das UCs brasileiras é escasso e isso é um obstáculo para gestão dessas áreas (Oliveira et al. 2017). Estimar a importância biológica das UCs de forma mais precisa é o primeiro passo para uma gestão e conservação mais eficientes. Além das UCs, outras áreas protegidas são também reconhecidas pelo Sistema Nacional de Unidades de Conservação (SNUC), tais como: as Reservas Legais, as Áreas de Preservação Permanente, as Reservas Indígenas e os sítios de proteção internacionais - Reservas da Biosfera, Sítios do Patrimônio da Humanidade e Sítios Ramsar (Medeiros \& Garay 2006).

As UCs podem estar distribuídas de forma a proteger diferentes formações fitoecológicas. A Mata Atlântica tem um mosaico vegetacional com grande biodiversidade (Rodrigues \& Brancalion 2009) e o Estado do Rio de Janeiro, que está totalmente inserido nesse bioma, é coberto por cinco formações fitoecológicas diferentes, a saber: Floresta Estacional Semidecidual, Floresta Ombrófila Densa, Formações Pioneiras, Floresta Ombrófila Mista e Savana Estépica (Costa et al. 2009). As três primeiras ocupavam a maior área do território, $20.567,46 \mathrm{~km}^{2}, 18.032,24 \mathrm{~km}^{2}$ e $3.706,65 \mathrm{~km}^{2}$, respectivamente (Costa et al. 2009). A Floresta Estacional Semidecidual e as Formações Pioneiras têm cerca de $90 \%$ de seus territórios sem vegetação. A Floresta Ombrófila Densa tem 18,7\% de sua vegetação protegida em UCs de Uso Sustentável ou de Proteção Integral, enquanto que as Formações Pioneiras e a Floresta Estacional Semidecidual, apenas $4,7 \%$ e $0,3 \%$, respectivamente (Costa et al. 2009). No Estado do Rio de Janeiro existem 48 UCs de Proteção Integral e 53 de Uso Sustentável nas esferas federais, estaduais e municipais. É um estado que pode ser considerado um dos melhores amostrados em relação aos morcegos (Bergallo et al. 2003, Stevens 2013), porém ainda existem áreas que possuem lacunas de conhecimento sobre ocorrência desses animais (Peracchi \& Nogueira 2010), como exemplo, as regiões do Médio Paraíba e Centro-Sul (Dias et al. 2010).

Neste sentido, estudos que identificam quais espécies não estão protegidas pelo sistema brasileiro de UCs, podem direcionar os esforços para o planejamento de conservação (Jennings 2000, Margules \& Pressey 2000). Assim, o objetivo deste estudo foi ( $i$ ) avaliar se as espécies ameaçadas de extinção de morcegos que ocorrem no Estado do Rio de Janeiro estão protegidas pelo SNUC, (ii) se há diferenças no número de espécies ameaçadas entre as regiões fitoecológicas e (iii) entre os tipos de UCs (Proteção Integral e Uso Sustentável) e localidades fora de UCs.

\section{MATERIAL E MÉTODOS}

Nós obtivemos os registros de ocorrência de espécies de morcegos ameaçadas de extinção no Estado do Rio de Janeiro, utilizando como base os dados do Laboratório de Diversidade de Morcegos (LADIM) da Universidade Federal Rural do Rio de Janeiro (UFRRJ), que foram obtidos a partir de amostragens realizadas entre os anos de 1989 e 2013. A esta base, incluímos dados provenientes das seguintes fontes de literatura: banco de teses da Coordenação de Aperfeiçoamento de Pessoal de Nível Superior (CAPES, http://www.capes.gov. $\mathrm{br} /$ servicos/banco-de-teses), Scientific Electronic Library Online (Scielo, http://www.scielo.org), Web of Science (WoS, http://www.webofknowledge. com) e Google Acadêmico (https://scholar.google. com.br/). Além disso, também analisamos dados em revistas especializadas usualmente preferidas por especialistas em quirópteros, mas que não constam em plataformas de publicações (i.e., Revista Brasileira de Zoociências e Chiroptera Neotropical). Consultamos também o banco de dados do SpeciesLink (http://splink.cria.org.br), além da consulta direta aos currículos dos principais pesquisadores da área através do sistema Lattes (http://lattes.cnpq.br). Utilizamos para todas as pesquisas bibliográficas a combinação das palavras- 
chave: “Chiroptera”, “Quiróptero”, “Morcego”, "Bat” e "Rio de Janeiro". As buscas foram realizadas no mês de dezembro de 2018.

Classificamos as espécies quanto ao estado de conservação, de acordo com as listas oficiais da fauna ameaçada de extinção do Brasil (ICMBio 2018) e do Estado do Rio de Janeiro (Bergallo et al. 2000). Devido à uma mudança taxonômica ocorrida após a lista estadual, na qual as populações de Lonchophylla bokermanni Sazima, Vizotto e Taddei, 1978 provenientes do Estado do Rio de Janeiro foram assinaladas como Lonchophylla peracchii Dias, Esbérard e Moratelli, 2013 (Dias et al. 2013), mantivemos a categorização de "vulnerável" dessas populações (Bergallo et al. 2000) por entendermos que há ameaça de extinção no nível regional (ver Teixeira et al. 2014).

Para avaliar se as espécies ameaçadas de extinção de morcegos estão protegidas pelo SNUC, sobrepomos suas coordenadas geográficas ao mapa do Estado do Rio de Janeiro e à camada vetorial de UCs (federais, estaduais e municipais). Para elaboração do mapa utilizamos arquivos vetoriais através do programa Quantum GIS 2.18.10 (QGIS Development Team 2016). Para os registros sem georreferenciamento, obtivemos as coordenadas mais próximas da localidade citada usando o Google Earth (https://www.google.com.br/intl/ptBR/earth/). Para as localidades não encontradas, consideramos as coordenadas centrais do município. Os dados de registros de morcegos ameaçados de extinção de cada localidade amostrada foram somados para a UC em que as localidades estão inseridas. Com isso a unidade amostral deste estudo foi cada UC do Estado do Rio de Janeiro. Em algumas situações, uma UC de Proteção Integral pode estar inserida em uma Área de Proteção Ambiental (APA). Nestes casos, as informações sobre a UC de Proteção Integral são somadas ao da APA, mas nunca o inverso.

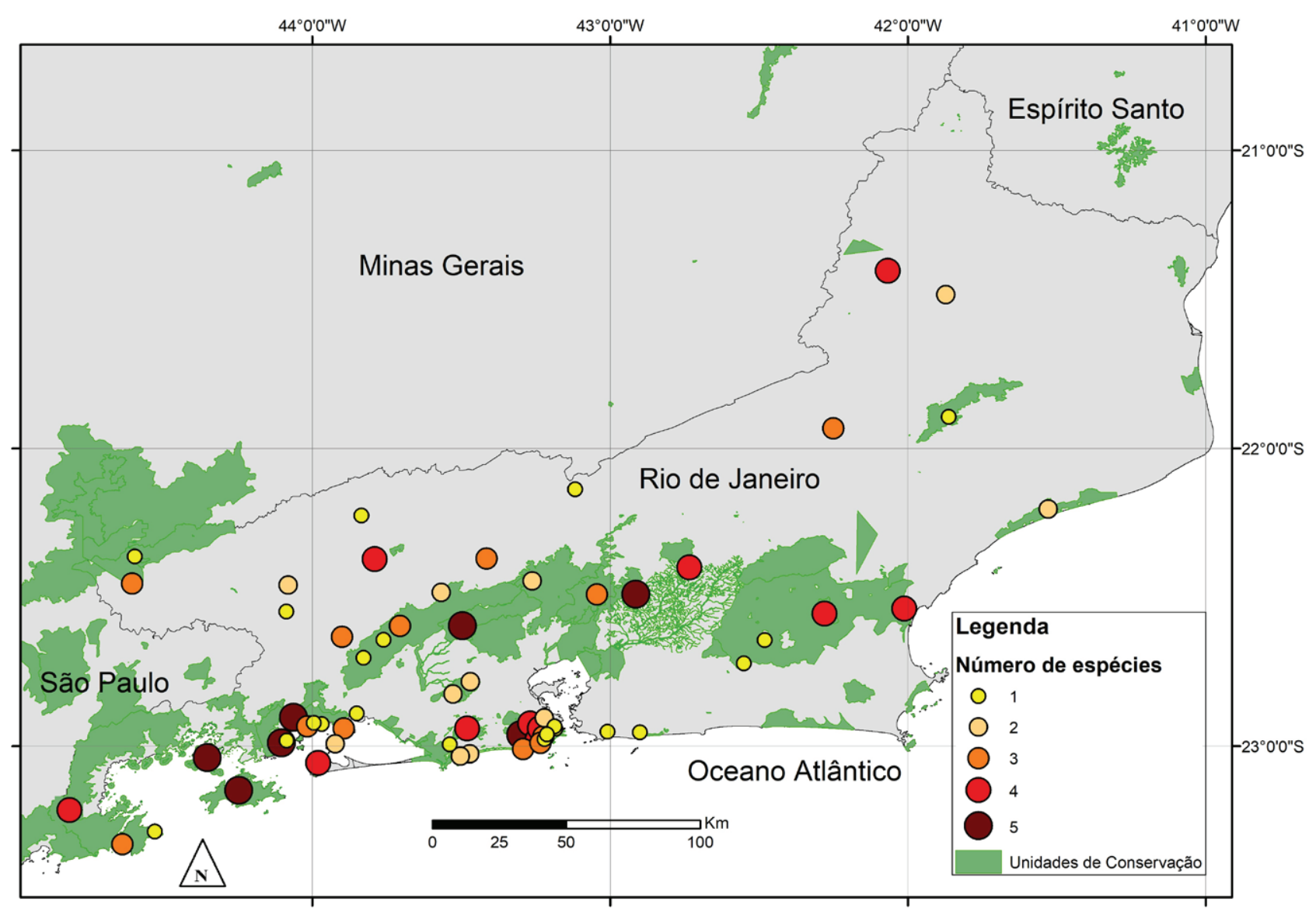

Figura 1. Mapa do Estado do Rio de Janeiro com todas as localidades com registros de espécies de morcegos ameaçadas de extinção.

Figure 1. Map of the State of Rio de Janeiro with all localities with records of threatened bat species. 
Para estimar a proporção da área protegida de cada espécie, somamos a área de todas as UCs que a espécie foi registrada. Foi obtido a porcentagem dessa área em relação a área total do Estado do Rio de Janeiro (IBGE, http://www.ibge.gov.br/ estadosat/perfil.php?sigla=rj). O esforço de captura foi calculado segundo Straube \& Bianconi (2002), porém algumas localidades não apresentavam esses dados. Para os dados sobre as formações fitoecológicas utilizamos como base Fidalgo et al. (2009).

Para avaliar se o número de espécies ameaçadas de extinção difere entre os tipos de UCs (Proteção Integral e Uso Sustentável) e em áreas fora de UCs, realizamos uma Análise de Covariância (ANCOVA) usando como covariável o esforço de captura. Quando ocorria sobreposição de UC de Proteção Integral com uma UC de Uso Sustentável, o número de espécies ameaçadas foi contabilizado para cada UC separadamente. A ANCOVA também foi utilizada para avaliar se o número de espécies ameaçadas diferia entre as regiões fitoecológicas. Nocaso de sobreposições deUC deProteção Integral com uma UC de Uso Sustentável, nós utilizamos um valor único do número total de espécies ameaçadas encontradas em ambas UCs para evitar pseudorepetições nas regiões fitoecológicas. Nós usamos o programa Systat 13 para a realização das análises e a elaboração dos gráficos.

\section{RESULTADOS}

Neste estudo compilamos dados de 45 localidades amostradas inseridas em 30 UCs e de 17 localidades que não estão inseridas em UCs (Figura 1 e Material Suplementar 1). Das sete espécies de morcegos ameaçadas no Brasil, três foram registradas no estado, enquanto no nível regional são consideradas 11 espécies (Tabela 1 ).

Natalus macrourus (única espécie considerada ameaçada tanto no Brasil quanto no estado) não foi registrada em UC e foi capturada em duas localidades fora de UC (Tabela 1), em Paraíso do Tobias, município de Miracema, e no município de Cantagalo. Furipterus horrens (ameaçada em nível nacional) foi a espécie registrada com a menor quantidade de área protegida em UC de Proteção Integral. Lonchorhina aurita foi a espécie ameaçada de extinção em nível nacional com mais registros, porém está protegida em apenas $4,41 \%$ da área total do estado em UC de Proteção Integral. Platyrrhinus recifinus foi a espécie ameaçada de extinção em nível regional que possuiu mais registros de ocorrência e com a maior quantidade de área protegida (Tabela 1).

A UC que apresentou um maior número de espécies ameaçadas em nível regional $(\mathrm{N}=7)$ foi o Parque Estadual Cunhambebe, porém possuía registro de apenas uma espécie ameaçada em nível nacional (L. aurita). A UC que apresentou um maior número de espécies ameaçadas em nível nacional $(\mathrm{N}=2)$ foi a APA Cairuçu, no entanto apenas duas espécies ameaçadas no nível regional foram registradas para a área (Tabela 2 ).

Em relação às localidades que não estão inseridas em UCs, Paraíso do Tobias, município de Miracema, teve, juntamente com o Santuário da Vida Silvestre Serra da Concórdia, municípios de Valença e Barra do Piraí, os maiores números de espécies ameaçadas $(\mathrm{N}=4$; Tabela 3$)$, no qual a primeira apresentou uma espécie ameaçada em nível nacional ( $N$. macrourus) e a segunda apenas espécies ameaçadas em nível regional. A localidade que apresentou um maior número de espécies ameaçadas em nível nacional foi a Gruta Pedra Santa $(\mathrm{N}=3)$, no município de Cantagalo, sendo que a única espécie ameaçada no nível regional foi N. macrourus, considerada também ameaçada em nível nacional.

A APA Mangaratiba, município de Mangaratiba, foi a UC com maior esforço de captura (512.325 h. $\mathrm{m}^{2}$ ) e o maior número de registros de espécies ameaçadas $(\mathrm{N}=8)$. Essa UC se sobrepõe com o Parque Estadual Cunhambebe, municípios de Angra dos Reis, Rio Claro, Mangaratiba e Itaguaí, que é a UC de Proteção Integral com maior esforço de captura (208.280 h.m²; Tabela 2). O resultado da ANCOVA entre as espécies ameaçadas e as regiões fitoecológicas, tendo como covariável o esforço de captura, foi significativo apenas para o esforço de captura $(F=16,140 ; p=0,001)$. As regiões fitoecológicas não tiveram efeito tanto isoladamente $(\mathrm{F}=0,721 ; \mathrm{p}=0,497)$, quanto na interação com o esforço de captura $(\mathrm{F}=0,948 ; \mathrm{p}=$ 0,403) no número de espécies ameaçadas (Figura 2). O resultado da ANCOVA entre as espécies ameaçadas e o tipo das UCs ou localidades fora de UC, tendo como covariável o esforço de captura, foi 


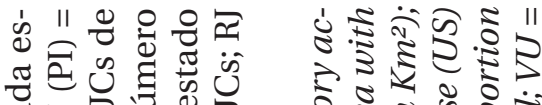

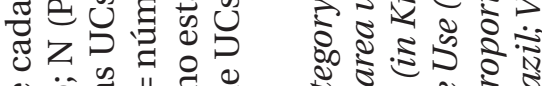

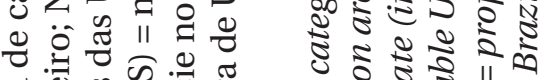

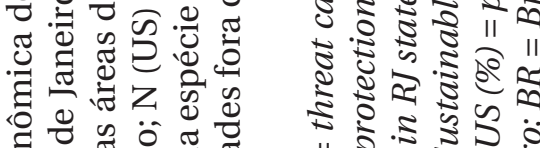

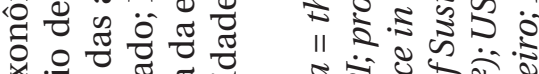
ख્व

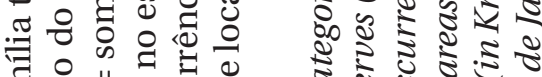

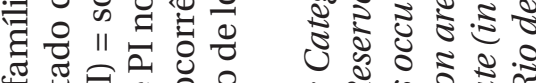

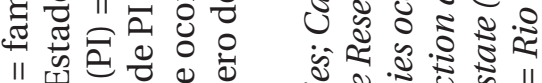

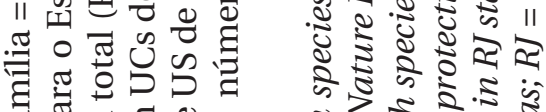

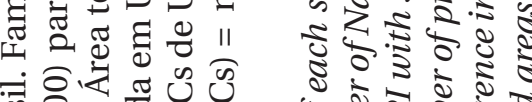

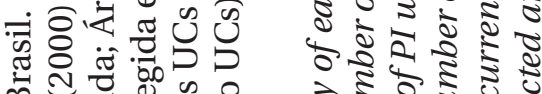

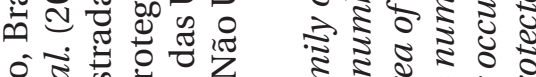

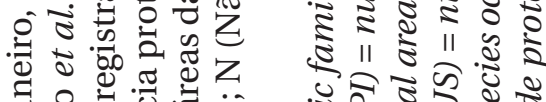
ำำรับ

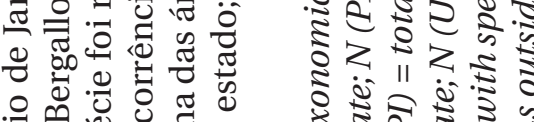

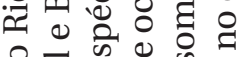

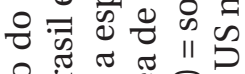

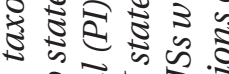

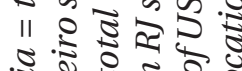
웄

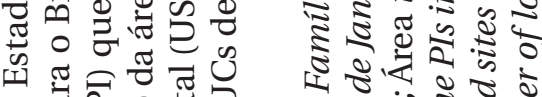

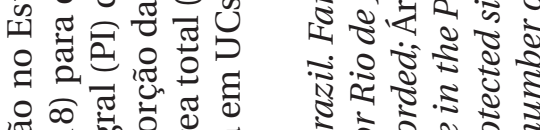

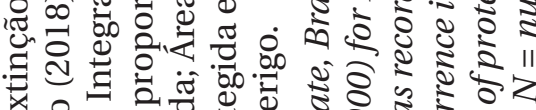

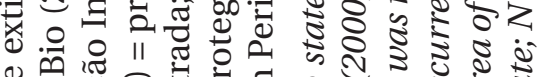
일

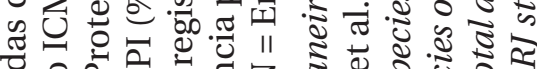

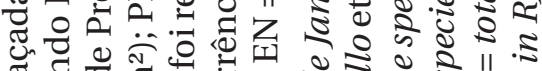

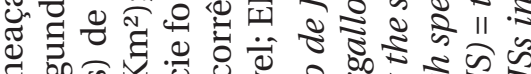

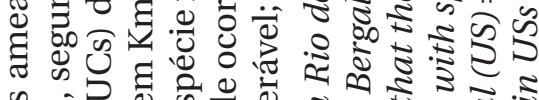

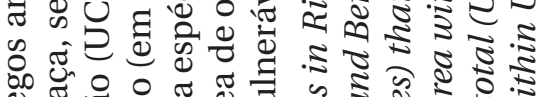

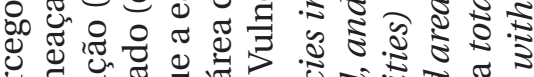
至

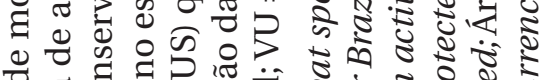

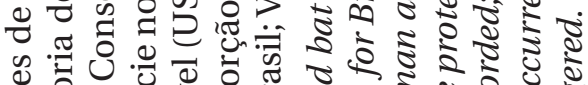

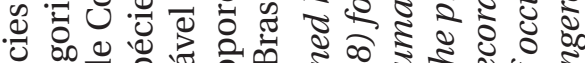

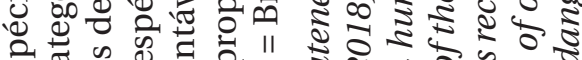

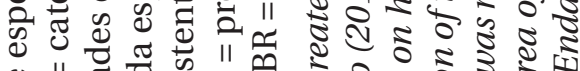
ช.

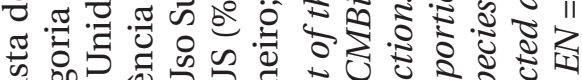

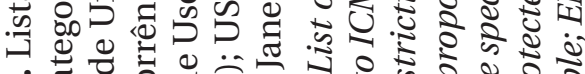

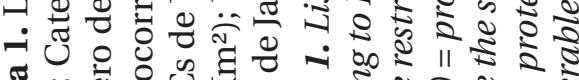

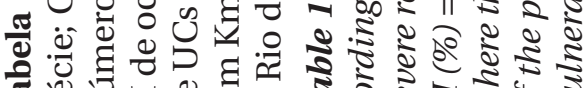

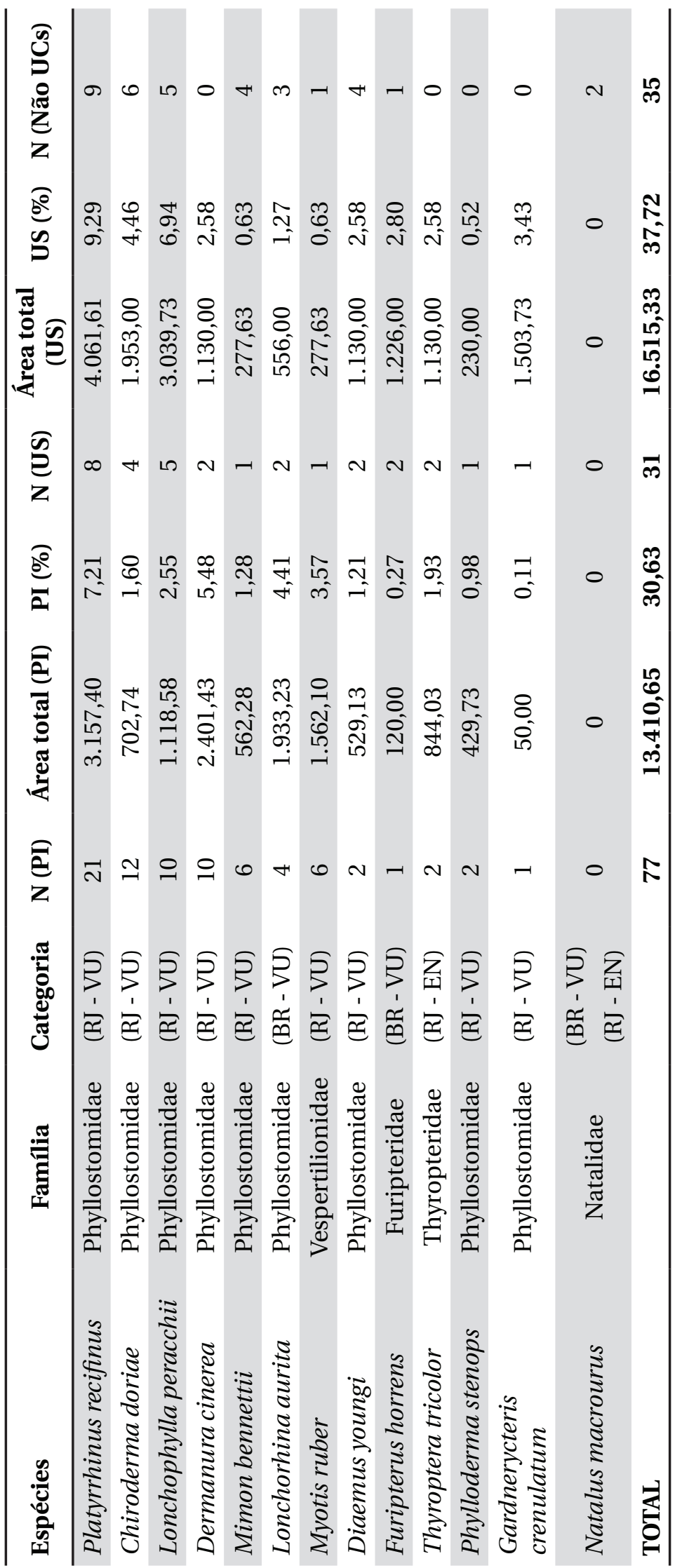


Tabela 2. Unidades de Conservação de Proteção Integral (PI) e Uso Sustentável (US) no Estado do Rio de Janeiro, Brasil, com registros de espécies ameaçadas de extinção em nível nacional (ICMBio 2018) e regional (Bergallo et al. 2000), regiões fitoecológicas (Fidalgo et al. 2009) e esforço de captura (Straube \& Bianconi 2002) da localidade. APA = Área de Proteção Ambiental; REBIO = Reserva Biológica. Os números entre parênteses referem-se à quantidade de espécies exclusivas da Unidade de Conservação de US. *Furipterus horrens foi capturada em refúgio (Pol et al. 2003).

Table 2. Protected areas of Nature Reserve (PI) and Sustainable Use (US) in the State of Rio de Janeiro, Brazil, with records of threatened species at national (ICMBio 2018) and regional (Bergallo et al. 2000) levels, phytoecological regions (Fidalgo et al. 2009) and capture effort (Straube \& Bianconi 2002) of each locality. APA = Environmental Protection Area; $R E B I O=$ Biological Reserve. Numbers in brackets quantify the unique species to protected areas of US. *Furipterus horrens was captured in roost (Pol et al. 2003).

\begin{tabular}{|c|c|c|c|c|c|c|}
\hline $\begin{array}{l}\text { Unidades de } \\
\text { Conservaçãoo }\end{array}$ & Categoria & $\begin{array}{c}\text { Nível } \\
\text { Nacional }\end{array}$ & $\begin{array}{c}\text { Nível } \\
\text { Regional }\end{array}$ & Total & Região Fitoecológica & $\begin{array}{r}\text { Esforço } \\
\left(\text { h.m }{ }^{2}\right) \\
\end{array}$ \\
\hline APA Mangaratiba & US & $1(0)$ & $7(4)$ & $8(4)$ & $\begin{array}{c}\text { Floresta Ombrófila } \\
\text { Densa }\end{array}$ & 512.325 \\
\hline $\begin{array}{l}\text { Parque Estadual } \\
\text { Cunhambebe }\end{array}$ & PI & 1 & 7 & 8 & $\begin{array}{c}\text { Floresta Ombrófila } \\
\text { Densa }\end{array}$ & 208.280 \\
\hline $\begin{array}{l}\text { Parque Estadual dos } \\
\text { Três Picos }\end{array}$ & PI & 1 & 6 & 7 & $\begin{array}{c}\text { Floresta Ombrófila } \\
\text { Densa }\end{array}$ & 130.237 \\
\hline APA Tamoios & US & $1(0)$ & $6(5)$ & $7(5)$ & $\begin{array}{c}\text { Floresta Ombrófila } \\
\text { Densa }\end{array}$ & - \\
\hline $\begin{array}{l}\text { Parque Estadual } \\
\text { da Ilha Grande }\end{array}$ & PI & 1 & 4 & 5 & $\begin{array}{c}\text { Floresta Ombrófila } \\
\text { Densa }\end{array}$ & - \\
\hline $\begin{array}{l}\text { Reserva Biológica do } \\
\text { Tinguá }\end{array}$ & PI & 0 & 6 & 6 & $\begin{array}{c}\text { Floresta Ombrófila } \\
\text { Densa }\end{array}$ & - \\
\hline $\begin{array}{l}\text { Parque Nacional da } \\
\text { Tijuca }\end{array}$ & PI & 0 & 6 & 6 & $\begin{array}{c}\text { Floresta Ombrófila } \\
\text { Densa }\end{array}$ & 124.127 \\
\hline $\begin{array}{l}\text { APA do Rio São João } \\
\text { Mico Leão Dourado }\end{array}$ & US & $0(0)$ & $6(5)$ & $6(5)$ & $\begin{array}{c}\text { Formações } \\
\text { Pioneiras/Floresta } \\
\text { Ombrófila Densa/ } \\
\text { Floresta Estacional } \\
\text { Semidecidual }\end{array}$ & 194.519 \\
\hline $\begin{array}{l}\text { REBIO de Poço } \\
\text { das Antas }\end{array}$ & PI & 0 & 4 & 4 & $\begin{array}{c}\text { Floresta Ombrófila } \\
\text { Densa }\end{array}$ & 130.497 \\
\hline $\begin{array}{l}\text { Estação Ecológica } \\
\text { Estadual Paraíso }\end{array}$ & PI & 1 & 4 & 5 & $\begin{array}{c}\text { Floresta Ombrófila } \\
\text { Densa }\end{array}$ & 81.326 \\
\hline APA Cairuçu & US & 2 & 2 & 4 & $\begin{array}{c}\text { Floresta Ombrófila } \\
\text { Densa }\end{array}$ & 2.940 \\
\hline $\begin{array}{l}\text { Parque Nacional da } \\
\text { Serra da Bocaina }\end{array}$ & PI & 1 & 3 & 4 & $\begin{array}{l}\text { Floresta Ombrófila } \\
\text { Densa/Floresta } \\
\text { Ombrófila Mista }\end{array}$ & 129.600 \\
\hline $\begin{array}{l}\text { Parque Natural } \\
\text { Municipal da Cidade }\end{array}$ & PI & 0 & 4 & 4 & $\begin{array}{c}\text { Floresta Ombrófila } \\
\text { Densa }\end{array}$ & 44.064 \\
\hline $\begin{array}{l}\text { Parque Estadual do } \\
\text { Grajaú }\end{array}$ & PI & 0 & 4 & 4 & $\begin{array}{c}\text { Floresta Ombrófila } \\
\text { Densa }\end{array}$ & 10.812 \\
\hline $\begin{array}{l}\text { Parque Estadual da } \\
\text { Pedra Branca }\end{array}$ & PI & 0 & 4 & 4 & $\begin{array}{c}\text { Floresta Ombrófila } \\
\text { Densa }\end{array}$ & - \\
\hline $\begin{array}{l}\text { APA Serra da } \\
\text { Mantiqueira }\end{array}$ & US & $0(0)$ & $3(1)$ & $3(1)$ & $\begin{array}{c}\text { Floresta Ombrófila } \\
\text { Densa }\end{array}$ & 43.330 \\
\hline
\end{tabular}

Tabela 2. Continua na próxima página... Table 2. Continued on next page... 
Tabela 2....Continuação

Table 2....Continued

\begin{tabular}{|c|c|c|c|c|c|c|}
\hline $\begin{array}{l}\text { Unidades de } \\
\text { Conservação }\end{array}$ & Categoria & $\begin{array}{c}\text { Nível } \\
\text { Nacional }\end{array}$ & $\begin{array}{c}\text { Nível } \\
\text { Regional }\end{array}$ & Total & Região Fitoecológica & $\begin{array}{r}\text { Esforço } \\
\left(\text { h.m }{ }^{2}\right)\end{array}$ \\
\hline $\begin{array}{l}\text { Parque Nacional } \\
\text { do Itatiaia }\end{array}$ & PI & 0 & 3 & 3 & $\begin{array}{c}\text { Floresta Ombrófila } \\
\text { Densa/Floresta } \\
\text { Estacional } \\
\text { Semidecidual }\end{array}$ & 33.195 \\
\hline $\begin{array}{l}\text { Parque Natural } \\
\text { Municipal do Curió }\end{array}$ & PI & 0 & 3 & 3 & $\begin{array}{c}\text { Floresta Ombrófila } \\
\text { Densa }\end{array}$ & 51.840 \\
\hline $\begin{array}{l}\text { APA do Gericinó- } \\
\text { Mendanha }\end{array}$ & US & 0 & 3 & 3 & $\begin{array}{c}\text { Floresta Ombrófila } \\
\text { Densa }\end{array}$ & 63.000 \\
\hline $\begin{array}{l}\text { Parque Municipal do } \\
\text { Penhasco Dois Irmãos }\end{array}$ & PI & 0 & 3 & 3 & $\begin{array}{c}\text { Floresta Ombrófila } \\
\text { Densa }\end{array}$ & 42.323 \\
\hline $\begin{array}{l}\text { Parque Nacional da } \\
\text { Serra dos Órgãos }\end{array}$ & PI & 0 & 3 & 3 & $\begin{array}{c}\text { Floresta Ombrófila } \\
\text { Densa }\end{array}$ & 8.172 \\
\hline $\begin{array}{l}\text { Parque Natural } \\
\text { Municipal Chico } \\
\text { Mendes }\end{array}$ & PI & 0 & 2 & 2 & Formações Pioneiras & 9.345 \\
\hline $\begin{array}{l}\text { Parque Natural } \\
\text { Municipal Fazenda } \\
\text { Santa Cecília do Ingá }\end{array}$ & PI & 0 & 2 & 2 & $\begin{array}{l}\text { Floresta Estacional } \\
\text { Semidecidual }\end{array}$ & 16.515 \\
\hline APA Guandu & US & 0 & 2 & 2 & $\begin{array}{c}\text { Floresta Ombrófila } \\
\text { Densa }\end{array}$ & 172.050 \\
\hline $\begin{array}{l}\text { Reserva Biológica de } \\
\text { Araras }\end{array}$ & PI & 0 & 2 & 2 & $\begin{array}{c}\text { Floresta Ombrófila } \\
\text { Densa }\end{array}$ & 66.297 \\
\hline $\begin{array}{l}\text { Parque Natural } \\
\text { Municipal da Prainha }\end{array}$ & PI & 0 & 2 & 2 & $\begin{array}{c}\text { Floresta Ombrófila } \\
\text { Densa }\end{array}$ & 15.900 \\
\hline $\begin{array}{l}\text { Parque Nacional } \\
\text { da Restinga de } \\
\text { Jurubatiba }\end{array}$ & PI & 0 & 2 & 2 & Formações Pioneiras & 33.559 \\
\hline $\begin{array}{l}\text { Parque Estadual da } \\
\text { Serra do Tiririca }\end{array}$ & PI & 0 & 1 & 1 & $\begin{array}{c}\text { Floresta Ombrófila } \\
\text { Densa }\end{array}$ & - \\
\hline $\begin{array}{l}\text { Parque Estadual do } \\
\text { Desengano }\end{array}$ & PI & 0 & 1 & 1 & $\begin{array}{c}\text { Floresta Ombrófila } \\
\text { Densa }\end{array}$ & 15.510 \\
\hline $\begin{array}{l}\text { Área de Relevante } \\
\text { Interesse Ecológico } \\
\text { Floresta da Cicuta }\end{array}$ & US & 0 & 1 & 1 & $\begin{array}{l}\text { Floresta Estacional } \\
\text { Semidecidual }\end{array}$ & 84.150 \\
\hline TOTAL & 29 & 7 & 91 & 98 & & \\
\hline
\end{tabular}

significativo, havendo interação entre esforço de captura e tipo das UCs ou localidades fora de UCs $\left(R^{2}=0,738 ; F=6,755 ; p=0,005\right)$ (Figura 3).

\section{DISCUSSÃO}

Das sete espécies de morcegos ameaçadas de extinção no Brasil, três têm registro no Estado do Rio de Janeiro. Dessas três espécies consideradas ameaçadas de extinção em nível nacional, $N$. macrourus é a única que não está protegida pelo SNUC no Estado do Rio de Janeiro. Ela foi capturada apenas em Floresta Estacional Semidecidual, que é a fitofisionomia com a menor porcentagem de área protegida por UCs (Costa et al. 2009). Neste estudo foi capturada em dois refúgios, sendo um deles a Gruta Pedra Santa (Esbérard et al. 1997, Esbérard et al. 2010). As localidades estão inseridas nas regiões Agropecuária dos Rios Pomba, Muriaé e Itabapoana 


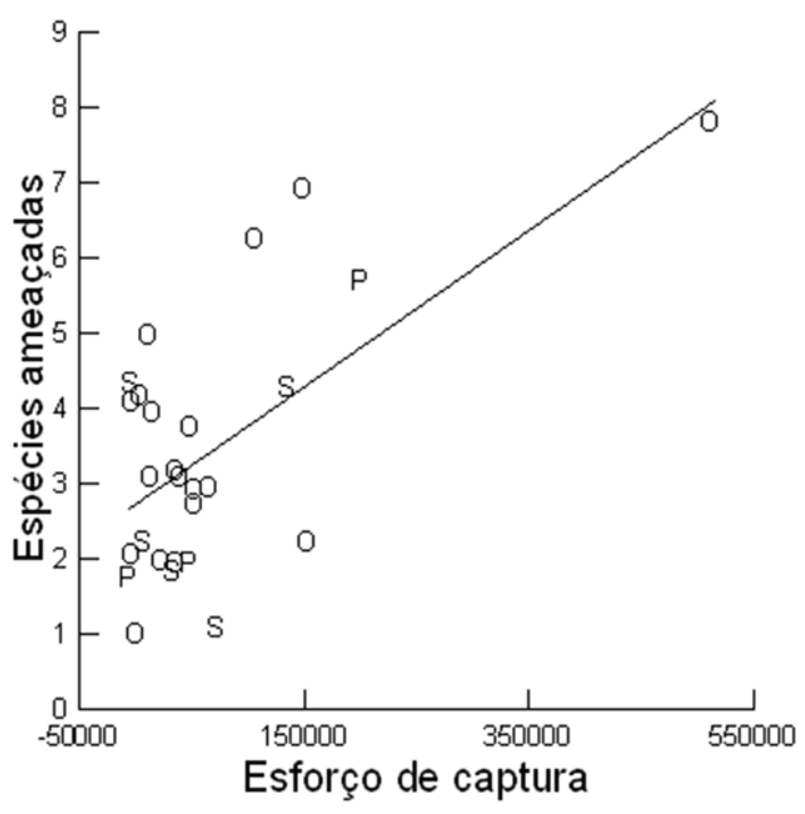

Figura 2. Relação entre espécies de morcegos ameaçadas de extinção e esforço de captura (h.m²) nas diferentes regiões fitoecológicas no Estado do Rio de Janeiro. A relação entre o número de espécies ameaçadas e o esforço de captura foi significativa $(p=0,001)$, porém não há efeito das regiões fitoecológicas. Legenda: $\mathrm{O}=$ Floresta Ombrófila Densa; P = Formações Pioneiras; $\mathrm{S}=$ Floresta Estacional Semidecidual.

Figure 2. Relationship between threatened bat species and capture effort $\left(h . m^{2}\right)$ in different phytoecological regions in Rio de Janeiro state. The relationship between the number of threatened bat species and the capture effort was significant $(p=0.001)$, but there is no effect of the phytoecological regions. Legend: $O=$ Dense Ombrophylous Forest; $P=$ Pioneer Formation Area; $S$ = Seasonal Semidecidual-Forest.

e Serrana de Economia Agropecuária, sendo caracterizadas por terem poucos remanescentes florestais e UCs (Costa 2014). Essa espécie pertence à Família Natalidae e ocorre em todos os estados do sudeste do Brasil (Tavares et al. 2008), sendo amplamente distribuída, porém localmente rara (Tejedor 2011, Rocha et al. 2013, Delgado-Jaramillo et al.2017) e possuindo uma forte associação com ambientes cavernícolas (ICMBio 2018). É uma espécie ameaçada de extinção em nível regional classificada como "em perigo" (Bergallo et al. 2000), e em nível nacional como "vulnerável” (ICMBio 2018).

Furipterus horrens, que pertence à família Furipteridae, também ocorre em todos os estados do sudeste do Brasil (Tavares et al. 2008), e é classificada como "vulnerável" em nível nacional (ICMBio 2018). É a espécie ameaçada de extinção

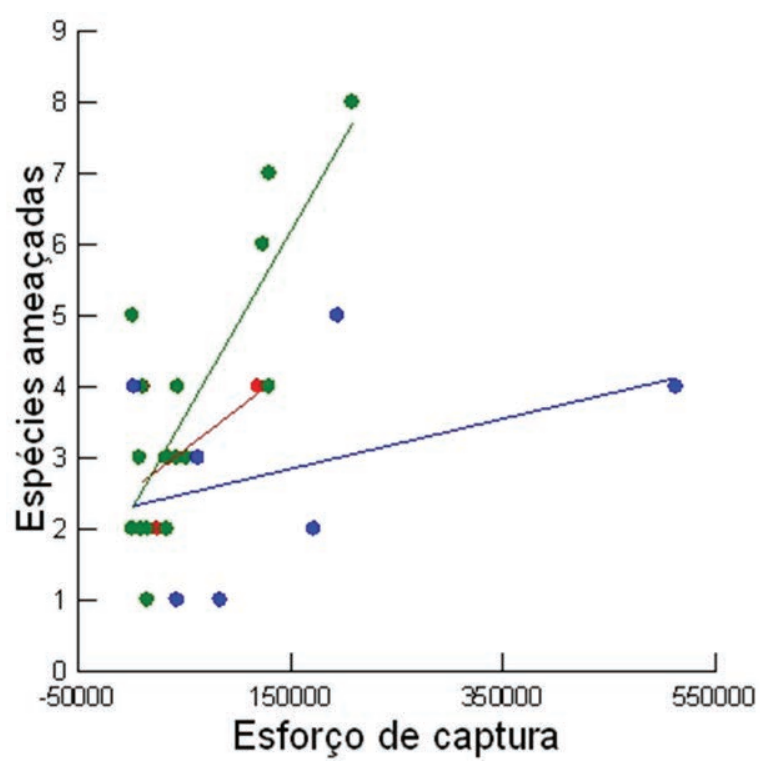

Figura 3. Relação entre o número de espécies de morcegos ameaçadas de extinção e esforço de captura (h.m²). O número de espécies ameaçadas foi afetado pela interação entre esforço de captura e categoria da localidade $(\mathrm{F}=6,755 ; \mathrm{p}=0,005)$. Legenda: $\mathrm{FO}=$ localidades fora de Unidades de Conservação (pontos vermelhos); PI = Unidades de Conservação de Proteção Integral (pontos verdes); US = Unidades de Conservação de Uso Sustentável (pontos azuis).

Figure 3. Relationship between the number of threatened bat species and capture effort $\left(h . \mathrm{m}^{2}\right)$. The number of threatened bat species is affected by the interaction between capture effort and locality category $(F=6.755, p=0.005)$. Legend: $F O=$ locations outside protected areas (red dots); PI = Nature Reserve (green dots); US = Sustainable Use area (blue dots).

presente em menor quantidade de área protegida em UC de Proteção Integral, não chegando a $1 \%$ da área do Estado do Rio de Janeiro. Foi capturada em seus refúgios na APA Cairuçu no município de Paraty (Pol et al. 2003), no Parque Estadual da Ilha Grande no município de Angra dos Reis (Esbérard et al. 2006) e na Gruta Pedra Santa no município de Cantagalo. Normalmente essa espécie é capturada em seus refúgios (Uieda et al. 1980, Trajano 1984), não sendo comum a captura em rede de neblina, que é o método mais frequentemente empregado para a captura de morcegos (Kunz \& Kurta 1988). Portanto, é possível que a espécie $F$. horrens seja subamostrada em toda sua área de ocorrência e sua abundância local desconhecida.

Lonchorhina aurita pertence à família Phyllostomidae, subfamília Lonchorhininae, é classificada como "vulnerável" em nível nacional 
(ICMBio 2018) e foi a espécie de morcego com o maior número de registros no estado, em comparação às demais ameaçadas nacionalmente. É conhecida por usar cavernas como abrigo (Voss \& Emmons 1996, Handley \& Ochoa 1997) e, a partir de nossos dados, ela foiregistrada na Gruta PedraSanta, município de Cantagalo. Portanto, seria esperado que sua distribuição refletisse a disponibilidade de cavernas cársticas, que são mais frequentemente encontradas na região norte do estado (Jansen et al. 2012). O maior número de registros para a espécie provém da região turística da Costa Verde, que não tem muitas grutas conhecidas, mas é uma região de potencialidade de ocorrência de cavernas (Jansen et al. 2012). Essa região está localizada na região sul do Estado do Rio de Janeiro e encontrase bem preservada e protegida por UCs (Van Sluys et al. 2009). É possível que redes armadas junto a corpos d'água podem prover melhor resultados na captura dessa espécie (Esbérard et al. 1997).

Plathirrynus recifinus foi a espécie com maior número de registros. Recebeu o status de ameaçada de extinção na categoria "vulnerável" em nível regional (Bergallo et al. 2000), apesar de ocorrer na maior parte do estado e ser considerada com ampla distribuição (Costa et al. 2011). Dados disponíveis em inventários indicam que $P$. recifinus vem sendo amostrada com maior frequência, presente tanto em áreas preservadas, quanto em áreas degradadas (e.g., Dias et al.2002, Esbérard et al. 2006, Moratelli \& Peracchi 2007, Dias \& Peracchi 2008, MenezesJúnior 2008, Modesto et al. 2008a, 2008b, Pinto 2008, Esbérard et al. 2010, Lourenço et al. 2010, Novaes et al. 2010a, Carvalho et al. 2011, Luz et al. 2011a, 2011b, Esbérard et al. 2013, Luz et al. 2013, Pereira 2013, Pereira et al. 2013, Gomes et al. 2015, Martins et al.2015). Esse aumento de registros pode ser explicado pois atualmente, distinguir P. recifinus de $P$. lineatus se tornou mais claro e evidente em virtude da publicação de revisões recentes do gênero e outros estudos taxonômicos relacionados (Velazco 2005, Tavares \& Velazco 2010), e do recente aumento de inventários em regiões do estado outrora desconhecidas.

O Parque Estadual Cunhambebe apresentou o maior número de espécies registradas. É uma UC de Proteção Integral que está dentro da APA Mangaratiba e está localizada na região turística

Tabela 3. Localidades não inseridas em Unidades de Conservação no Estado do Rio de Janeiro com registros de espécies ameaçadas de extinção em nível nacional (ICMBio 2018) e regional (Bergallo et al. 2000), município, regiões fitoecológica (Fidalgo et al. 2009) e esforço de captura (Straube \& Bianconi 2002) da localidade.

Table 3. Localities with no legal protection in the State of Rio de Janeiro with records of threatened species at national (ICMBio 2018) and regional (Bergallo et al. 2000) levels, municipality, phytoecological regions (Fidalgo et al. 2009) and capture effort (Straube \& Bianconi 2002) of the locality.

\begin{tabular}{|c|c|c|c|c|c|c|}
\hline Localidades & $\begin{array}{c}\text { Nível } \\
\text { Nacional }\end{array}$ & $\begin{array}{c}\text { Nível } \\
\text { Regional }\end{array}$ & Total & Município & $\begin{array}{l}\text { Formação } \\
\text { Fitoecológica }\end{array}$ & $\begin{array}{r}\text { Esforço } \\
\left(\text { h.m }{ }^{2}\right) \\
\end{array}$ \\
\hline Paraíso do Tobias & 1 & $4^{*}$ & 4 & Miracema & $\begin{array}{l}\text { Floresta Estacional } \\
\text { Semidecidual }\end{array}$ & 11.232 \\
\hline $\begin{array}{l}\text { Santuário da Vida Silvestre } \\
\text { Serra da Concórdia }\end{array}$ & 0 & 4 & 4 & Valença & $\begin{array}{l}\text { Floresta Estacional } \\
\text { Semidecidual }\end{array}$ & 119.797 \\
\hline Gruta Pedra Santa & 3 & $1^{*}$ & 3 & Cantagalo & $\begin{array}{l}\text { Floresta Estacional } \\
\text { Semidecidual }\end{array}$ & - \\
\hline $\begin{array}{l}\text { Jardim Botânico do Rio de } \\
\text { Janeiro }\end{array}$ & 0 & 3 & 3 & $\begin{array}{l}\text { Rio de } \\
\text { Janeiro }\end{array}$ & $\begin{array}{c}\text { Floresta Ombrófila } \\
\text { Densa }\end{array}$ & 34.814 \\
\hline Barra & 0 & 3 & 3 & $\begin{array}{l}\text { Rio de } \\
\text { Janeiro }\end{array}$ & Formações Pioneiras & - \\
\hline Paty do Alferes & 1 & 2 & 3 & $\begin{array}{l}\text { Paty do } \\
\text { Alferes }\end{array}$ & $\begin{array}{l}\text { Floresta Estacional } \\
\text { Semidecidual/ } \\
\text { Floresta Ombrófila } \\
\text { Densa } \\
\end{array}$ & - \\
\hline
\end{tabular}

Tabela 3. Continua na próxima página... Table 3. Continued on next page... 
Tabela 3. ...Continuação

Table 3. ...Continued

\begin{tabular}{|c|c|c|c|c|c|c|}
\hline Localidades & $\begin{array}{c}\text { Nível } \\
\text { Nacional }\end{array}$ & $\begin{array}{c}\text { Nível } \\
\text { Regional }\end{array}$ & Total & Município & $\begin{array}{l}\text { Formação } \\
\text { Fitoecológica }\end{array}$ & $\begin{array}{l}\text { Esforço } \\
\left(\mathbf{h . m ^ { 2 }}\right)\end{array}$ \\
\hline Piraí & 0 & 3 & 3 & Piraí & $\begin{array}{l}\text { Floresta Estacional } \\
\text { Semidecidual/ } \\
\text { Floresta Ombrófila } \\
\text { Densa }\end{array}$ & - \\
\hline Monte Verde & 1 & 1 & 2 & Cambuci & $\begin{array}{l}\text { Floresta Estacional } \\
\text { Semidecidual }\end{array}$ & 25.238 \\
\hline Quinta da Boa Vista & 0 & 2 & 2 & $\begin{array}{l}\text { Rio de } \\
\text { Janeiro }\end{array}$ & $\begin{array}{c}\text { Floresta Ombrófila } \\
\text { Densa }\end{array}$ & 10.125 \\
\hline Inoã & 0 & 1 & 1 & Maricá & $\begin{array}{c}\text { Floresta Ombrófila } \\
\text { Densa }\end{array}$ & - \\
\hline Três Rios & 0 & 1 & 1 & Três Rios & $\begin{array}{l}\text { Floresta Estacional } \\
\text { Semidecidual }\end{array}$ & - \\
\hline Laranjeiras & 0 & 1 & 1 & $\begin{array}{l}\text { Rio de } \\
\text { Janeiro }\end{array}$ & $\begin{array}{c}\text { Floresta Ombrófila } \\
\text { Densa }\end{array}$ & - \\
\hline Botafogo & 0 & 1 & 1 & $\begin{array}{l}\text { Rio de } \\
\text { Janeiro }\end{array}$ & $\begin{array}{c}\text { Floresta Ombrófila } \\
\text { Densa }\end{array}$ & - \\
\hline Gávea & 0 & 1 & 1 & $\begin{array}{l}\text { Rio de } \\
\text { Janeiro }\end{array}$ & $\begin{array}{c}\text { Floresta Ombrófila } \\
\text { Densa }\end{array}$ & - \\
\hline Guaratiba & 0 & 1 & 1 & $\begin{array}{l}\text { Rio de } \\
\text { Janeiro }\end{array}$ & $\begin{array}{c}\text { Floresta Ombrófila } \\
\text { Densa/Formações } \\
\text { Pioneiras }\end{array}$ & - \\
\hline Valença & 0 & 1 & 1 & Valença & $\begin{array}{l}\text { Floresta Estacional } \\
\text { Semidecidual }\end{array}$ & - \\
\hline Coroa Grande & 0 & 1 & 1 & Itaguaí & $\begin{array}{c}\text { Floresta Ombrófila } \\
\text { Densa }\end{array}$ & - \\
\hline TOTAL & 6 & 31 & 37 & & & \\
\hline
\end{tabular}

* Apenas uma espécie está ameaçada tanto em nível regional quanto nacional (Natalus macrourus), incluída em ambos os somatórios mas considerada apenas uma vez no número total de espécies ameaçadas por localidade.

* Only one species is threatened at regional and national levels (Natalus macrourus) and was included in both, but counted once in total number of threatened species by site.

da Costa Verde. Esse parque estadual foi área de amostragem de seis localidades e alto esforço de capturas, resultando em diversos estudos sobre diversidade e aspectos da biologia de quirópteros (Esbérard et al. 1997, Esbérard \& Bergallo 2004, Costa et al. 2006, Costa et al. 2007, Esbérard et al. 2007, Costa et al. 2008, Esbérard \& Bergallo 2008, Esbérard 2009, Bolzan et al. 2010, Esbérard \& Bergallo 2010, Novaes et al.2010b, Costa \& Esbérard 2011, Costa et al. 2011, Esbérard et al. 2011a, 2011b, Luz et al. 2011b, Esbérard 2012, Luz et al.2015).

A APA Cairuçu, que teve registro de duas espécies ameaçadas em nível nacional (F. horrens e L. aurita - ambas na categoria "vulnerável"), também está localizada na região turística da Costa
Verde. Dentro dessa UC está localizada a Reserva Ecológica Estadual da Juatinga que está em fase de recategorização em cumprimento à lei do SNUC, mas não está disponível para qual tipo de UC (INEA 2019). As duas localidades aqui estudadas: a Praia do Sono (duas noites de amostragem) e a Praia da Sumaca, com apenas uma espécie registrada capturada em refúgio (Pol et al. 2003), estão localizadas no município de Paraty. Existem poucos estudos nesse município, localizado no extremo sudoeste do estado. Além dessas duas localidades, um estudo com maior duração foi realizado nesse munícipio, no Parque Nacional da Serra da Bocaina (Delcielos et al. 2018).

Paraíso do Tobias teve registro de quatro 
espécies ameaçadas, sendo uma em nível nacional (ver Esbérard et al. 2010). Está localizado na região norte do Estado do Rio de Janeiro, que dentre as poucas áreas ainda com resquícios de Mata Atlântica, encontram-se aglomerados de fragmentos de Floresta Estacional Semidecidual, entre os municípios de Miracema e Laje do Muriaé (Bergallo et al. 2009, Fidalgo et al. 2009), mas a cobertura de campos e pastagens é predominante (Saraça et al. 2009). Paraíso do Tobias está próximo (cerca de $10 \mathrm{~km}$ ) ao Refúgio da Vida Silvestre Ventania, e à cerca de $40 \mathrm{~km}$ do Parque Estadual do Desengano.

O Santuário da Vida Silvestre da Serra da Concórdia também apresentou quatro espécies ameaçadas de extinção, mas nenhuma em nível nacional. Essa localidade situa-se no município de Valença também em região de Floresta Estacional Semidecidual (Fidalgo et al. 2009). O local de amostragem está localizado no maciço Serra da Concórdia, que circunda o Parque Estadual da Serra da Concórdia (PESC) (Modesto et al. 2008a). Apesar do Santuário da Vida Silvestre da Serra da Concórdia não ser uma UC, é uma reserva privada responsável pela proteção de 220 ha de floresta (Modesto et al. 2008a). Além disso, a proximidade com o PESC, que atualmente possui quase seis mil hectares de áreas protegidas (Decreto Estadual no 45.766, de 28 de setembro de 2016) possivelmente favorece a presença de espécies ameaçadas de extinção na região.

Gruta Pedra Santa foi a localidade com maior número de registros de espécies ameaçadas em nível nacional. Essa gruta está localizada no município de Cantagalo, que apresenta um importante fragmento de Floresta Estacional Semidecidual por ser o mais representativo do Vale do Paraíba (Fidalgo et al. 2009). O Estado do Rio de Janeiro possui 23 cavernas registradas na Sociedade Brasileira de Espeleologia atualmente, sendo a Gruta Pedra Santa a maior delas, e, segundo o Mapa de Potencialidade de Ocorrência de Cavernas no Brasil (IBGE-CECAV, Jansen et al. 2012), a região noroeste do estado apresenta um grau de potencialidade muito alto. Considerando que as três espécies de morcegos ameaçadas nacionalmente são altamente dependentes de cavernas (ICMBio 2018), é possível que este seja o fator determinante para a presença dessas espécies na região. Vale ressaltar que a presença de indústrias de cimento que extraem matéria-prima de cavernas ameaçam severamente a fauna cavernícola da região (Fidalgo et al.2009).

A UC com maior esforço de captura teve um maior número de registros de espécies de morcegos ameaçadas. O uso de um longo esforço de captura pode favorecer a aproximação da amostragem da riqueza real de uma localidade (Voss \& Emmons 1996, Bergallo et al.2003, Stevens 2013), podendo amostrar mais espécies, inclusive aquelas consideradas raras. Unidades de Conservação que não foram amostradas ou que foram pouco amostradas devem ser prioridade para os inventários de biodiversidade (Oliveira et al. 2017). Além disso, é importante destacar que algumas espécies foram capturadas em seus refúgios. As capturas em refúgios podem interferir na quantidade de espécies obtida em uma localidade (Fenton 1997, Esbérard \& Bergallo 2008, Luz et al. 2011a).

As UCs de Proteção Integral tiveram, com menor esforço de captura, maior número de espécies de morcegos ameaçadas, seguida pelas áreas que não estão em UCs. A presença de espécies mais raras em UCs de Proteção Integral era de se esperar (e.g., Dias et al. 2002, Esbérard 2003, Esbérard et al. 2006, Dias \& Peracchi 2008, Mello 2009, Luz et al. 2011c, Delcielos et al. 2018), pois são localidades onde os habitats estão mais protegidos, por serem locais com objetivo básico de preservar a natureza, sendo admitido apenas o uso indireto dos seus recursos naturais (Brasil 2000 - Lei no 9.985/2000 Art. $7^{\circ}$ ). A presença de espécies de morcegos ameaçadas de extinção em locais não protegidos é importante para chamar a atenção destas áreas que necessitam mais esforços de preservação.

Listas regionais de espécies ameaçadas de extinção podem permitir conclusões mais consistentes, além de, em conjunto, promover melhor conhecimento sobre a situação real da fauna brasileira (Bergallo et al. 2000). Porém, mostra-se necessário considerar que a única lista de espécies ameaçadas de extinção para o Estado do Rio de Janeiro está desatualizada, pois foi elaborada há aproximadamente 20 anos (junho de 1998; Bergallo et al. 2000). Os autores dessa lista definiram os critérios e as categorias de ameaça baseados naqueles propostos na época pela União Mundial para a Conservação da Natureza (IUCN), que teve modificações ao longo do tempo. Para classificar uma espécie dentro das categorias considerou-se o tamanho da área de distribuição da espécie, as 
alterações ambientais ocorridas em seu hábitat, a capacidade adaptativa da espécie e o tamanho e a variação populacional (Van Sluys et al. 2000).

Neste estudo observamos que a única espécie ainda sem registros em UCs no Estado do Rio de Janeiro foi $N$. macrourus, encontrada em regiões do estado com poucos remanescentes florestais e áreas protegidas. Sendo assim, os municípios de Miracema e Cantagalo, são importantes áreas para conservação e preservação de morcegos, não estando sob proteção legal. As localidades fora de UCs que apresentaram mais espécies ameaçadas de extinção são regiões caracterizadas por terem poucos remanescentes florestais e UCs. Assim, é fundamental a inserção dessas localidades em alguma UC já existente, para a conservação da biodiversidadelocal.A Reserva Ecológica Estadual da Juatinga é uma localidade com forte pressão turística e concordamos que merece a recategorização por ser ainda um local bem preservado protegendo espécies ameaçadas de extinção.

De acordo com o observado, as espécies de morcegos ameaçadas de extinção que ocorrem no Estado do Rio de Janeiro estão pouco protegidas por UCs, uma vez que em média apenas 1,6\% das áreas protegem tais espécies por serem UCs de Proteção Integral e 2,6\% por serem UCs de Uso Sustentável. Esse dado se torna mais preocupante quando consideramos que as UCs de Uso Sustentável são as mais alteradas por diminuição da sua área por políticas públicas no país (Bernard et al. 2014). Algumas espécies de morcegos ameaçadas de extinção não estão ou são pouco protegidas pela rede de UCs do estado, em especial as que ocorrem em Floresta Estacional Semidecidual. Esta região cobre $48 \%$ do território do estado, porém apenas 0,3\% está protegido em UCs (Costa et al. 2009), necessitando urgentemente que as áreas com vegetação remanescente sejam protegidas para garantir a conservação das espécies.

\section{AGRADECIMENTOS}

LMC agradece à Fundação Carlos Chagas Filho de Amparo à Pesquisa do Estado do Rio de Janeiro (FAPERJ) pela bolsa de doutorado entre 2012 e 2014 (Bolsa Nota 10) e a atual bolsa de pós-doutorado PAPDRJ (E-26/101.399/2014). GRW agradece ao
Conselho Nacional de Desenvolvimento Científico e Tecnológico (CNPq) pela bolsa de pós-doutorado (processo n. 206876/2017-3). JLL agradece ao CNPq. HGB agradece FAPERJ pela bolsa de Cientísta do Nosso Estado (E-26/202.757/2017, E-26/103.016/2011), Prociência/UERJ e CNPq pela bolsa de produtividade (307781/2014-3, 457458/2012-7). CELE agradece a FAPERJ pela bolsa de Jovem Cinetísta do Nosso Estado (E26/102.201/2009 e E-26/102.960/2012) e CNPq pela bolsa de produtidade (301061/2007-6, 300272/2010-3 e 306808/2014-5). Agradecemos aos proprietários das áreas e a administração das Unidades de Conservação pelas autorizações de coletas.

\section{REFERÊNCIAS}

Albuquerque, H. G., Martins, P. F., Pessôa, F. S., Modesto, T. C., Luz, J. L., Raíces, D. S. L., Ardente, N. C., Lessa, I. C. M., Attias, N., Jordão-Nogueira, T., Enrici, M. C., \& Bergallo, H. G. 2013. Mammals of a forest fragment in Cambuci municipality, state of Rio de Janeiro, Brazil. Check List, 9(6), 1505-1509. DOI: 10.15560/9.6.1505

Bergallo, H. G., Rocha, C. F. D., Alves, M. A. S., \&Van Sluys, M. 2000. A Fauna ameaçada de extinção do estado do Rio de Janeiro. Rio de Janeiro: EDUERJ: p. 168.

Bergallo, H. G., Esbérard, C. E. L., Mello, M. A. R., Lins, V., Mangolin, R., Melo, G. G. S., \& Baptista, M. 2003. Bat species richness in Atlantic Forest: what is the minimum sampling effort? Biotropica, 35(2), 278-288. DOI: 10.1646/02033 Bergallo, H. G., Vicens, R. S., Baptista, R. L. C., Bomtempo, C. B. T., Saraça, C. E. S., Baptista, D. F., Silva, H. R., \& Salgado, N. C. 2019. Região Agropecuária dos Rios Pomba, Muriaé e Itabapoana. In: H. G. Bergallo, E. C. C. Fidalgo, C. F. D. Rocha, M. C. Uzêda, M. B. Costa, M. A. S. Alaves, M. Van Sluys, M. A. Santos, T. C. C. Costa \& A. C. R. Cozzolino (Eds.), Estratégias e ações para a conservação da biodiversidade no Estado do Rio de Janeiro. pp. 293-302. Rio de Janeiro: Instituto Biomas.

Bernard, E., Penna, L. A. O, \& Araújo, E. 2014. Downgrading, downsizing, degazettement, and reclassification of protected areas in Brazil. 
Conservation Biology, 28(4), 939-950. DOI: 10.1111/cobi.12298

Bernardo, C. 2007. Unidades de Conservação: comentários à Lei 9.985/2000. Rio de Janeiro: Letra Capital: p. 119.

Bolzan, D. P., Lourenço, E. C., Costa, L. M., Lins, J. L., Nogueira, T. J., Dias, D., Esbérard, C. E. L., \& Peracchi, A. L. 2010. Morcegos da região da Costa Verde e adjacências, Litoral Sul do Estado do Rio de Janeiro. Chiroptera Neotropical, 16(1), 586-595.

Brasil. 2000. Lei no 9.985/2000 Art. 7º, de 18 de julho de 2000. Regulamenta o art. 225, $\$ 1^{\circ}$, incisos I, II, III e VII da Constituição Federal, institui o Sistema Nacional de Unidades de Conservação da Natureza e dá outras providências. Acesso em 04 de janeiro de 2019, em http://www.planalto. gov.br/ccivil_03/LEIS/L9985.htm

Carvalho, W. D., Freitas, L. N., Freitas, G. P., Luz, J. L., Costa, L. M., \& Esbérard, C. E. L. 2011. Efeito da chuva na captura de morcegos em uma ilha da costa sul do Rio de Janeiro, Brasil. Chiroptera Neotropical, 17(1), 808-816.

Costa, L. M. 2014. Conservação de morcegos no estado do Rio de Janeiro: como e onde já foram amostrados e que locais merecem atenção. Tese de Doutorado. Departamento de Ecologia da Universidade do Estado do Rio de Janeiro. p. 127.

Costa, L. M, \& Esbérard, C. E. L. 2011. Desmodus rotundus (Mammalia: Chiroptera) on the southern coast of Rio de Janeiro state. Brazilian Journal of Biology, 71(3), 739-746. DOI: 10.1590/ S1519-69842011000400020

Costa, L. M., Prata, A. F. D., Moraes, D., Conde, C. F. V, Jordão-Nogueira, T., \& Esbérard, C. E. L. 2006. Deslocamento de Artibeus fimbriatus sobre o mar. Chiroptera Neotropical, 12(2), 289-290.

Costa, L. M., Almeida, J. C., \& Esbérard, C. E. L. 2007. Dados de reprodução de Platyrrhinus lineatus em estudo de longo prazo no Estado do Rio de Janeiro (Mammalia, Chiroptera, Phyllostomidae). Iheringia, 97 (2), 152-156. DOI: 10.1590/S0073-47212007000200004

Costa, L. M., Oliveira, D. M., Fernandes, A. F. P. D., \& Esbérard, C. E. L. 2008. Ocorrência de Diaemus youngi (Jentink 1893), Chiroptera, no Estado do Rio de Janeiro. Biota Neotropica, 8(1), 217-220. DOI: 10.1590/S1676-06032008000100023

Costa, T. C. C., Fidalgo, E. C. C., Santos, R. F.,
Rocha, J. V., Metzger, J. P., Vicens, R. S., TanizakiFonseca, K., \& Bohrer, C. B. A. 2009. Diversidade de paisagens no Estado do Rio de Janeiro. In: $\mathrm{H}$. G. Bergallo, E. C. C. Fidalgo, C. F. D Rocha, M. C. Uzêda, M. B. Costa, M. A. S. Alves, M. Van Sluys, M. A. Santos, T. C. C. Costa \& A. C. R. Cozzolino (Eds.). Estratégias e ações para a conservação da biodiversidade no Estado do Rio de Janeiro. pp. 101-110. Rio de Janeiro: Instituto Biomas.

Costa, L. M., Dias, D., Freitas, G. P., Carvalho, W. D., Luz, J. L., \& Esbérard CEL. 2011. Distribuição geográfica e abundância de Platyrrhinus recifinus no Estado do Rio de Janeiro, sudeste do Brasil. Chiroptera Neotropical, 17(1), 62-66.

Delcielos, A. C., Motta, A., Dias, D., Almeida, B. \& Rocha-Barbosa, O. 2018. Bats of the Serra da Boicana National Park, southeastern Brazil: an update species list and distribution extension for Trinycteris nicefori (Sanborn, 1949). Biota Neotropica, 18(4), e20180537. DOI: 10.1590/1676-0611-BN-2018-0537

Delgado-Jaramillo, M., Barbier, E., \& Bernard, E. 2017. New records, potential distribution, and conservation of the Near Threatened cave bat Natalus macrourus in Brazil. Oryx, 52(3), 579-586. DOI: 10.1017/S0030605316001186

Dias, D., \& Peracchi, A. L. 2008. Quirópteros da Reserva Biológica do Tinguá, estado do Rio de Janeiro, sudeste do Brasil (Mammalia: Chiroptera). Revista Brasileira de Zoologia, 25(2), 333-369. DOI: 10.1590/S010181752008000200023

Dias, D., Silva, S. S. P., \& Peracchi AL. 2002. Quirópteros do ParqueEstadual da Pedra Branca, Rio de Janeiro, RJ (Mammalia: Chiroptera). Revista Brasileira de Zoologia, 19(2), 113-140. DOI: 10.1590/S0101-81752002000600012

Dias, D., Pereira, S. N., Maas, A. C. S., Martins, M. A., Bolzan, D. P., \& Peracchi, A. L. 2010. Quirópteros das regiões Centro-Sul e Médio Paraíba do estado do Rio de Janeiro (Mammalia, Chiroptera). Chiroptera Neotropical, 16(1), 579585.

Dias, D., Esbérard, C. E. L., \& Moratelli, R. 2013. A new species of Lonchophylla (Chiroptera, Phyllostomidae) from the Atlantic Forest of southeastern Brazil, with comments on $L$. bokermanni. Zootaxa, 3722(3), 347-360. DOI: 10.11646/zootaxa.3722.3.4

Esbérard, C. E. L. 2003. Diversidade de morcegos em 
área de Mata Atlântica regenerada no sudeste do Brasil. Revista Brasileira de Zoociências, 5(2), 189-204.

Esbérard, C.E.L. 2007. Influência do ciclo lunar na captura de morcegos Phyllostomidae. Iheringia, 97(1), 81-85. DOI: 10.1590/S007347212007000100012

Esbérard, C. E. L. 2009. Capture sequence and relative abundance of bats during surveys. Revista Brasileira de Zoologia, 26(1), 103-108. DOI: 10.1590/S1984-46702009000100016

Esbérard, C. E. L. 2012. Activity and reproduction of Eptesicus brasiliensis (Chiroptera;Vespertilionidae) in the Rio de Janeiro State, Southeastern Brazil. Mammalia, 76, 49-55. DOI: 10.1515/mamm.2011.104

Esbérard, C. E. L., \& Bergallo, H. G. 2008. Influência do esforço amostral na riqueza de espécies de morcegos no sudeste do Brasil. Revista Brasileia de Zooogia, 25, 67-73. DOI: 10.1590/S010181752008000100010

Esbérard, C. E. L, \& Bergallo, H. G. 2010. Biology of Vampyressa pusilla (Wagner) in Rio de Janeiro State, Southeastern Brazil (Mammalia, Chiroptera, Phyllostomidae). Brazilian Journal of Biology, 70(2), 367-371. DOI: 10.1590/S151969842010005000019

Esbérard, C. E. L., Chagas, A. S., Baptista, M., \& Luz, E. M. 1996. Levantamento de Chiroptera na Reserva Biológica de Araras, Petrópolis, Rio de Janeiro - I - riqueza de espécies. Revista Científica do Instituto de Pesquisa Gonzaga da Gama Filho, 2, 65-87.

Esbérard, C. E. L., Martins, L. F. S., Cruz, R. C., Costa, R. C., Nunes, M. S., Luz, E. M., \& Chagas, A. S. 1997. Aspectos da biologia de Lonchorhina aurita no Estado do Rio de Janeiro (Mammalia: Chiroptera: Phyllostomidae). Revista Bioikos, $11(1,2), 46-49$.

Esbérard, C. E. L., Jordão-Nogueira, T., Luz, J. L., Melo, G. G. S., Mangolin, R., Jucá, N., Raíces, D. S., Enrici, M. C., \& Bergallo, H. G. 2006. Morcegos da Ilha Grande, Angra dos Reis, RJ, Sudeste do Brasil. Revista Brasileira de Zoociências, 8(2), 151-157.

Esbérard, C. E. L., Santos, B. S., \& Faria, D. 2007. New Thyroptera tricolor Spix records in the Atlantic Forest, Brazil (Chiroptera: Thyropteridae). Brazilian Journal of Biology, 67(2), 379-380. DOI: 10.1590/S1519-69842007000200028
Esbérard, C. E. L., Baptista, M., Costa, L. M, Luz, J. L., \& Lourenço, E. C. 2010. Morcegos de Paraíso do Tobias, Miracema, Rio de Janeiro. Biota Neotropica, 10(4), 249-255. DOI: 10.1590/ S1676-06032010000400030

Esbérard, C. E. L., Lima, I. P., Nobre, P. H., Althoff, S. L., Jordão-Nogueira, T., Dias, D., Carvalho, F, Fabián, M. E., Sekiama, M. L., Sobrinho, A. S. 2011a. Evidence of vertical migration in the Ipanema bat Pygoderma bilabiatum (Chiroderma: Phyllostomidae: Stenodermatinae). Zoologia, 28(6), 717-724. DOI: 10.1590/S1984-46702011000600004

Esbérard, C. E. L., Freitas, G. P., Luz, J. L., Costa, L. M., \& Freitas, L. N. 2011b. Intervalos máximos entre captura e recaptura de morcegos no estado do Rio de Janeiro, sudeste do Brasil. Chiroptera Neotropical, 17(1), 957-962.

Esbérard, C. E. L., Costa, L. M., \& Luz, J. L. 2013. Morcegos de Morro de São João, Estado do Rio de Janeiro, Sudeste do Brasil. Bioscience Journal, 29(2), 449-457.

Fearnside, P. M., \& Ferraz J. 1995. A conservation gap analysis of Brazil's Amazonian vegetation. Conservation Biology, 9(5), 1134-1147. DOI: 10.1046/j.1523-1739.1995.9051127.x-i1

Fenton, M. B. 1997. Science and the conservation of bats. Journal of Mammalogy, 78(1), 1-14. DOI: $10.2307 / 1382633$

Fidalgo, E. C. C., Uzêda, M. C., Bergallo, H. G., Costa, T. C., \& Abreu, M. B. 2009. Distribuição dos remanescentes vegetais do estado do Rio de Janeiro. In: H. G. Bergallo, E. C. C. Fidalgo, C. F. D Rocha, M. C. Uzêda, M. B. Costa, M. A. S. Alves, M. Van Sluys, M. A. Santos, T. C. C. Costa \& A. C. R. Cozzolino (Eds.), Estratégias e ações para a conservação da biodiversidade no Estado do Rio de Janeiro. pp. 91-99. Rio de Janeiro: Instituto Biomas.

Gomes, L. A. C., Pires, A. S., Martins, M. A., Lourenço, C. L., \& Peracchi, A. L. 2015. Species composition and seasonal variation in abundance of Phyllostomidae bats (Chiroptera) in an Atlantic Forest remnant, southeastern Brazil. Mammalia, 79(1), 61-68. DOI: 10.1515/ mammalia-2013-0108

Gomes, L. A. C., \& Esbérard, C. E. L. 2017. Longterm bat study on an island in the southeastern Brazilian coast with comparison of richness and composition of species among sites. Studies on 
Neotropical Fauna and Environment, 52(1), 4352.DOI: $10.1080 / 01650521.2016 .1272168$

Handley, JR., C. O., \& Ochoa-G. J. 1997. New species of mammals from northern South America: a sword-nosed bat, genus Lonchorhina Tomes (Chiroptera: Phyllostomidae). Memoria de la Sociedad de Ciencias Naturales La Salle, 57, 71-82.

Hutson, A. M., Mickleburgh, S. P., \& Racey, P. A.. 2001. Global status survey and conservation action plan. Microchiropteran bats. London: Information Press: p. 254.

IBAMA \& WWF-Brasil. 2007. Efetividade de gestão das Unidades de Conservação Federais do Brasil. Brasil: Edições IBAMA: p. 96.

ICMBio - Instituto Chico Mendes de Conservação da Biodiversidade. 2018. Livro vermelho da fauna brasileira ameaçada de extinção: Volume II Mamíferos. Brasília, DF : ICMBio/MMA.

INEA - Instituto Estadual do Ambiente. 2019. Reserva Ecológica Estadual da Juatinga. Acesso em 02 de janeiro de 2019, em http:// www.inea.rj.gov.br/Portal/Agendas / BIODIVERSIDADEEAREASPROTEGIDAS / UnidadesdeConservacao/INEA_008605

IUCN - International union for conservation of nature. 1994. Guidelines protected area management categories. Gland: IUCN: p. 66.

Jansen, D. C, Cavalcanti, L. F., \& Lamblém, H. S. 2012. Mapa de potencialidade de ocorrência de cavernas no Brasil, na escala 1:2.500.000. Revista Brasileira de Espeleologia, 2(1), 42-57.

Jennings, M. D. 2000. Gap analysis: concepts, methods, and recent results. Landscape Ecology, 15, 5-20. DOI: 10.1023/A:1008184408300

Kalko, E. K. V., Handley, C. O., Handley, D. 1996. Organization, diversity, and long-term dynamics of a Neotropical bat community. In: M. Cody \& J. Smallwood (Eds.), Long-term studies in vertebrate communities. pp. 503-553.Los Angeles:Academic Books.

Kunz, T. H., \& Kurta, A. 1988. Capture methods and holding devices. In: T. H. Kunz (Eds.), Ecological and behavioral methods for the study of bats. pp. 1-29. Washington, DC: Smithsonian Institution Press.

Kunz, T. H., Torrez, E. B., Bauer, D., Lobova, T., \& Fleming, T. H. 2011. Ecosystem services provided by bats. Annals of the New York Academy of Sciences, 1223, 1-38. DOI: 10.1111/j.17496632.2011.06004.x
Lourenço, E. C., Costa, L. M., Silva, R. M., \& Esbérard, C. E. L. 2010. Bat diversity of Ilha da Marambaia, southern Rio de Janeiro State, Brazil (Chiroptera, Mammalia). Revista Brasileira de Biologia, 70(3), 511-519. DOI: 10.1590/S151969842010000300007

Lourenço, C.P., Gomes, L.A.C.,Pinheiro, M.C.,Patrício, P. M. P, \& Famadas, K. M. 2014. Compositions of bat assemblages (Mammalia: Chiroptera) in tropical riparian forests. Zoologia, 31(4): 361-369. DOI: $10.1590 /$ S1984-46702014000400007

Luz,J. L., Jordão-Nogueira, T., Costa, L. M., Esbérard, C. E. L. 2011a. Observações sobre Eptesicus furinalis (d Orbigny e Gervais 1847) (Vespertilionidae) em forros no Estado do Rio de Janeiro, Brasil. Chiroptera Neotropical, 17, 826-831.

Luz, J. L., Costa, L. M., Lourenço, E. C., \& Esbérard, C. E. L. 2011b. Morcegos (Mammalia, Chiroptera) da Reserva Rio das Pedras, Rio de Janeiro, Sudeste do Brasil. Biota Neotropica, 11(1), 95-101. DOI: 10.1590/S1676-06032011000100009

Luz, J. L., Mangolin, R., Esbérard, C. E. L., \& Bergallo, H. G. 2011c. Morcegos (Chiroptera) capturados em lagoas do Parque Nacional da Restinga de Jurubatiba, Rio de Janeiro, Brasil. Biota Neotropica, 11, 161-168. DOI: 10.1590/S167606032011000400016

Luz, J. L., Costa, L. M., Jordão-Nogueira, T., Esbérard, C. E. L., \& Bergallo, H. G. 2013. Morcegos em área deFloresta Montana, Visconde de Mauá, Resende, Rio de Janeiro. Biota Neotropica, 13(2), 190-195. DOI: 10.1590/S1676-06032013000200018

Luz, J. L., Costa, L. M., \& Esbérard, C. E. L. 2015. Variação de recursos alimentares e abundância de morcegos em plantações de banana. Oecologia Australis, 19(1), 244-260. DOI: 10.4257/ oeco.2015.1901.16

Margules, C. R., \& Pressey, R. L. 2000. Systematic conservation planning. Nature, 405, 243-253. DOI: $10.1038 / 35012251$

Martins, M. A., Carvalho, W. D., Dias, D. França, D. S., Oliveira, M. B., \& Peracchi, A. L. 2015. Bat species richness (Mammalia, Chiroptera) along an elevational gradient in the Atlantic Forest of Southeastern Brazil. Acta Chiropterologiaca, 17(2), 401-409. DOI:10.3161/15081109A CC2015.17.2.016

Medeiros, R., \& Garay, I. 2006. Singularidades do sistema de áreas protegidas no Brasil e sua importância para a conservação da 
biodiversidade e o uso sustentável de seus componentes. In: I. E. G. Garay \& B. K. Becker (Orgs), Dimensões humanas da biodiversidade: o desafio de novas relações sociedade-natureza no século XXI. pp. 159-184. Petrópolis: Editora Vozes.

Mello, M. A. R. 2009. Temporal variation in the organization of a Neotropical assemblage of leaf-nosed bats (Chiroptera: Phyllostomidae). Acta Oecologica, 35, 280-286. DOI: 10.1016/j. actao.2008.11.008

Mello, M. A. R., \& Schittini, G. M. 2005. Ecological Analysis of three bat assemblages from conservation units in the lowland atlantic forest of Rio de Janeiro, Brazil. Chiroptera Neotropical, 11, 206-210.

Menezes-Júnior, L. F. 2008. Morcegos da Serra do Mendanha, Rio de Janeiro, RJ, Brasil (Mammalia, Chiroptera). Dissertação de Mestrado. Departamento de Biologia Animal da Universidade Federal Rural do Rio de Janeiro. p. 61.

Modesto, T. C., Pêssoa, F. S., Jordão-Nogueira, T., Enrici, M. C., Costa, L. M., Attias, N., Almeida, J., Raíces, D. S. L., Albuquerque, H. G., Pereira, B. C., Esbérard, C. E. L., \& Bergallo, H. G. 2008a. Mammals, Serra da Concórdia, state of Rio de Janeiro, Brazil. Check List, 4(3), 341-348. DOI: 10.15560/4.3.341

Modesto, T. C., Pessôa, F. S., Enrici, M. C., Attias, N., Jordão-Nogueira, T., Costa, L. M., Albuquerque, H. G., \& Bergallo, H. G. 2008b. Mamíferos do Parque Estadual do Desengano, Rio de Janeiro, Brasil. Biota Neotropica, 8(4), 152-159. DOI: 10.1590/S1676-06032008000400015

Moratelli, R., \& Peracchi, A. L. 2007. Morcegos (Mammalia, Chiroptera) do Parque Nacional da Serra dos Órgãos. In: C. Cronemberger \& E. B. V. Castro (Orgs.), Ciência e Conservação na Serra dos Órgãos. pp. 193-210. Brasília, DF: IBAMA.

Novaes, R. L. M., Sant'Anna, C., Silvares, R., Felix, S., Souza, R. F., Dias-de-Oliveira, L. F. C., Siqueira, A. C., Façanha, A. C. S., Cardoso, T. S., Louro, M., Aguiar, M. V. P., Andrade, P. C., Mello, F. A. P., Nobre, C. C., \& Peracchi, A. L. 2010a. Riqueza e diversidade de morcegos no Parque Natural Municipal de Nova Iguaçu, Rio de Janeiro, Brasil. Chiroptera Neotropical, 16(1), 137-139.

Novaes, R. L. M., Mello, F. A. P., Felix, S., Silvares, R., Sant'Anna, C., Façanha, A. C. S., Cardoso,
T. S., Louro, M. A. S., Souza, R. F., Aguiar, M. V. P., Siqueira, A. C., \& Esbérard, C. E. L. 2010b. Lonchophylla bokermanni na Floresta Atlântica: distribuição, conservação e nova localidade de ocorrência para uma espécie ameaçada de extinção. Chiroptera Neotropical, 16(2), 710714 .

Oliveira, U., Soares-Filho, B. S., Paglia, A. P., Brescovit, A. D., Carvalho, C. J. B., Silva, D. P., Rezende, D. T., Fortes-Leite, F. S., Batista, J. A. N., Barbosa, J. P. P. P., Stemann, J. R., Ascher, J. S., De Marco, P., Löwenberg-Neto, P., Gianluppi Ferro, V., \& Santos, A. J. 2017. Biodiversity conservation gaps in the Brazilian protected areas. Scientific reports, 7(9141), 1-9. DOI: 10.1038/s41598-01708707-2

Peracchi, A. L., \& Nogueira, M. R. 2010. Lista anotada dos morcegos do Estado do Rio de Janeiro, sudeste do Brasil. Chiroptera Neotropical, 16(1), 508-519.

Pereira, S. N. 2013. Inventário e aspectos biológicos de quirópteros (Mammalia, Chiroptera) da localidade de Morro Azul, Engenheiro Paulo de Frontin, RJ. Dissertação de Mestrado. Departamento de Biologia Animal da Universidade Federal Rural do Rio de Janeiro. p. 30.

Pereira, S. N., Dias, D., Lima, I. P., Maas, A. C. S., Martins, M. A., Bolzan, D. P., França, D. S., Oliveira, M. B., Peracchi, A. L. \& Ferreira, M. S. F. 2013. Mamíferos de um fragmento florestal em Volta Redonda, Estado do Rio de Janeiro. Bioscience Journal, 29(4), 1017-1027.

Pinto, A. C. D. C. 2008. Comunidade de Quirópteros (Mammalia, Chiroptera) do Parque Natural Municipal da Prainha, Rio de Janeiro, RJ, Brasil. Dissertação de Mestrado. Departamento de Biologia Animal da Universidade Federal Rural do Rio de Janeiro. p. 62.

Pol, A., Nogueira, M. R., \& Peracchi, A. L. 2003. Primeiro registro da família Furipteridae (Mammalia, Chiroptera) para o Estado do Rio de Janeiro, Brasil. Revista Brasileira de Zoologia, 20(3), 561-563. DOI: 10.1590/S010181752003000300031

QGIS Development Team. 2016. QGIS Geographic Information System. Open Source Geospatial Foundation Project.

Reis, N. R., Peracchi, A. L., Pedro, W. A., \& Lima, I. P. 2007a. Morcegos do Brasil. Londrina: 
Universidade Estadual de Londrina: p. 253.

Reis, N. R., Shibatta, O. A., Peracchi, A. L., Pedro, W. A., \& Lima, I. P. 2007b. Sobre os morcegos brasileiros. In: N. R. Reis, A. L. Peracchi, W. A. Pedro \& I. P. Lima (Eds.), Morcegos do Brasil. pp. 17-26. Londrina: Universidade Estadual de Londrina.

Rocha, P., Mikalauskas, J., Bocchiglieri, A., Feijó, J., \& Ferrari, S. 2013. An update on the distribution of the Brazilian Funnel-eared Bat, Natalus macrourus (Gervais, 1856) (Mammalia, Chiroptera), with new records from the Brazilian Northeastern. Check List, 9(3), 675-679. DOI: 10.15560/9.3.675

Rodrigues, R. R., \& Brancalion, P. H. S. 2009. Pacto pela restauração da Mata Atlântica: referencial dos conceitos e ações de restauração florestal. São Paulo: LERF/ESALQ: Instituto BioAtlântica: p. 256.

Rylands, A. B., \& Brandon, K. 2005. Unidades de Conservação brasileiras. Megadiversidade, 1(1), 27-35.

Rylands, A. B., \& Pinto, L. P. S. 1998. Conservação da biodiversidade na Amazônia brasileira: uma análise do sistema de Unidades de Conservação. Fundação Brasileira para o Desenvolvimento Sustentável, FBDS, 1, 1-65.

Saraça, C. E. S, Rahy, I. S., Santos, M. A., Costa, M. B., Alencar, R. S., \& Peres, W. R. 2009. A propósito de uma nova regionalização para o Estado do Rio de Janeiro. In: H. G. Bergallo, E. C. C. Fidalgo, C. F. D. Rocha, M. C. Uzêda, M. B. Costa, M. A. S. Alaves, M. Van Sluys, M. A. Santos, T. C. C. Costa \& A. C. R. Cozzolino (Eds.), Estratégias e ações para a conservação da biodiversidade no Estado do Rio de Janeiro. pp. 33-40. Rio de Janeiro: Instituto Biomas.

Simmons, N. B. 2005. Order Chiroptera. In: D. E. Wilson, D. M. Reeder (Eds), Mammal species of the world: a taxonomic and geographic reference. pp. 312-529. Baltimore: Johns Hopkins University Press.

Souza, R. F., Novaes, R. L. M., Siqueira, A. C., Jacob, C. S. G., Santos, C. E. L., Feliz, S., Ribeiro, E., Sant'Anna, C., Vrcibradic, D., Avilla, L. S., Sbragia, I., \& Santori, R. T. 2015. Morcegos (Mammalia, Chiroptera) em remanescente de Floresta Atlântica, Rio de Janeiro, sudeste do Brasil. Neotropical Biology and Conservation, 10(1), 9-14. DOI: 10.4013/nbc.2015.101.02
Stevens R. D. 2013. Gradients of bat diversity in Atlantic Forest of South America: environmental seasonality, sampling effort and spatial autocorrelation. Biotropica, 45(6), 764-770. DOI: $10.1111 /$ btp.12056

Straube, F. C., \& Bianconi, G. V. 2002. Sobre a grandeza e a unidade utilizada para estimar esforço de captura com utilização de rede-deneblina. Chiroptera Neotropical, 8(1-2), 150152.

Tavares, V. C., Gregorin, R., Peracchi, A. L. 2008. Diversidade de morcegos no Brasil: lista atualizada com comentários sobre distribuição e taxonomia. In: S. M. Pacheco, R. V. Marques \& C. E. L. Esbérard (Orgs). Morcegos no Brasil: biologia, sistemática, ecologia e conservação. pp 25-58. Porto Alegre: Armazém Digital.

Tavares, V. C., \& Velazco, P. M. 2010. Platyrrhinus recifinus (Chiroptera: Phyllostomidae). Mammalian Species, 42, 119-123. DOI: 10.1644/859.1

Teixeira, S. C., \& Peracchi, A. L. 1996. Morcegos do Parque Estadual da Serra da Tiririca, Rio de Janeiro, Brasil (Mammalia, Chiroptera). Zoologia 13, 61-66. DOI: 10.1590/S010181751996000100005

Teixeira, T. S. M., Weber, M. M., Dias, D., Lorini, M. L., Esbérard, C. E. L., Novaes, R. L. M., Cerqueira, R., \& Vale, M. M. 2014. Combining environmental suitability and habitat connectivity to map rare or Data Deficient species in Tropics. Journal for Nature Conservation, 22(4), 384-390. DOI: 10.1016/j.jnc.2014.04.001

Tejedor, A. 2011. Systematics of Funnel-Eared Bats (Chiroptera: Natalidae). New York, USA: American Museum of Natural History: p. 139.

Trajano, E. 1984. Ecologia de populações de morcegos cavernícolas em uma região cárstica do Sudeste do Brasil. Revista Brasileira de Zoologia, 2(5), 255-320. DOI: 10.1590/S010181751984000100001

Tylianakis, J. M., Didham, R. K., Bascompte, J., \& Wardle, D. A. 2008. Global change and species interactions in terrestrial ecosystems. Ecology Letters, 11, 1351-1363. DOI: 10.1111/j.14610248.2008.01250.x

Uieda, W., Sazima, I., \& Storti-Filho, A. 1980. Aspectos da biologia do morcego Furipterus horrens. Revista Brasileira de Biologia, 40(1), 59-66. 
Van Sluys, M., Alves, M. A. S., Bergallo, H. G., \& Rocha, C. F. D. 2000. O status de conservação da fauna do Estado do Rio de Janeiro: metodologia de avaliação. In: H. G. Bergallo, C. F. D Rocha, M. A. S. Alves \& M. Van Sluys (Eds), A Fauna ameaçada de extinção do estado do Rio de Janeiro. pp. 37-44. Rio de Janeiro: EDUERJ.

Van Sluys, M., Santos, S. B., Mazzoni, R., Thiengo, S. C., Santos, F., Creed, J. C., Marone, E., Oliveira, A. F., Irving, M. A., Maia, A. C. C. S. T., \& Rocha, R. T. 2009. Região Turística da Costa Verde. In: H. G. Bergallo, E. C. C. Fidalgo, C. F. D. Rocha, M. C. Uzêda, M. B. Costa, M. A. S. Alaves, M. Van Sluys, M. A. Santos, T. C. C. Costa, \& A. C. R Cozzolino (Eds). Estratégias e ações para a conservação da biodiversidade no Estado do Rio de Janeiro. pp. 339-343. Rio de Janeiro: Instituto Biomas.

Velazco, P. M. 2005. Morphological phylogeny of the bat genus Platyrrhinus Saussure, 1860 (Chiroptera: Phyllostomidae) with the description of four new species. Fieldiana: Zoology, newseries, 105,1-53.DOI:10.3158/00150754(2005) 105[1:MPOTBG]2.0.CO;2

Voigt, C. C., \& Kingston, T. 2016. Bats in the Anthropocene: conservation of bats in a changing world. Springer Open. DOI: 10.1007/978-3-319-25220-9

Voss, R. S., \& Emmons, L. H. 1996. Mammalian diversity in Neotropical lowland rainforests: a preliminary assessment. Bulletin of the American Museum of Natural History, 230, $1-115$.

Material Suplementar 1. Localidades amostradas, Unidades de Conservação e referências

bibliográficas. *LADIM: Dados coletados pelo Laboratório de Diversidade de Morcegos/ Universidade Federal Rural do Rio de Janeiro.

Suplementary Material 1. Localities sampled, Protected areas and references. *LADIM: Data collected by the Laboratório de Diversidade de Morcegos/Universidade Federal Rural do Rio de Janeiro.
Submetido em: 15/06/2018

Aceito em: $11 / 04 / 2019$

Publicado online: 15/06/2019

Editores Associados: Ana Cláudia Delciellos, Izar Araújo Aximoff \& Clarissa Alves da Rosa 